\title{
Ablation of TRPV1 Abolishes Salicylate-Induced Sympathetic Activity Suppression and Exacerbates Salicylate-Induced Renal Dysfunction in Diet-Induced Obesity
}

\author{
Beihua Zhong ${ }^{1}$, Shuangtao Ma ${ }^{1}$ and Donna H. Wang ${ }^{1,2,3, *}$ \\ 1 Division of Nanomedicine and Molecular Intervention, Department of Medicine, Michigan State University, \\ East Lansing, MI 48824, USA; beihuazhong@mail.com (B.Z.); mashuang@msu.edu (S.M.) \\ 2 Neuroscience Program, Michigan State University, East Lansing, MI 48824, USA \\ 3 Cell and Molecular Biology Program, Michigan State University, East Lansing, MI 48824, USA \\ * Correspondence: wangdo@msu.edu; Tel.: +1-517-432-0797
}

check for

updates

Citation: Zhong, B.; Ma, S.; Wang, D.H. Ablation of TRPV1 Abolishes Salicylate-Induced Sympathetic Activity Suppression and Exacerbates Salicylate-Induced Renal Dysfunction in Diet-Induced Obesity. Cells 2021, 10, 1234. https://doi.org/10.3390/ cells10051234

Academic Editor: Alexander E. Kalyuzhny

Received: 10 March 2021

Accepted: 14 May 2021

Published: 18 May 2021

Publisher's Note: MDPI stays neutral with regard to jurisdictional claims in published maps and institutional affiliations.

Copyright: (c) 2021 by the authors. Licensee MDPI, Basel, Switzerland. This article is an open access article distributed under the terms and conditions of the Creative Commons Attribution (CC BY) license (https:// creativecommons.org/licenses/by/ $4.0 /)$.

\begin{abstract}
Sodium salicylate (SA), a cyclooxygenase inhibitor, has been shown to increase insulin sensitivity and to suppress inflammation in obese patients and animal models. Transient receptor potential vanilloid 1 (TRPV1) is a nonselective cation channel expressed in afferent nerve fibers. Cyclooxygenase-derived prostaglandins are involved in the activation and sensitization of TRPV1. This study tested whether the metabolic and renal effects of SA were mediated by the TRPV1 channel. Wild-type (WT) and TRPV1 ${ }^{-/-}$mice were fed a Western diet (WD) for 4 months and received SA infusion $(120 \mathrm{mg} / \mathrm{kg} /$ day) or vehicle for the last 4 weeks of WD feeding. SA treatment significantly increased blood pressure in WD-fed TRPV1 ${ }^{-/-}$mice $(p<0.05)$ but not in WD-fed WT mice. Similarly, SA impaired renal blood flow in TRPV1 ${ }^{-/-}$mice $(p<0.05)$ but not in WT mice. SA improved insulin and glucose tolerance in both WT and TRPV1 ${ }^{-/-}$mice on WD (all $\left.p<0.05\right)$. In addition, SA reduced renal p65 and urinary prostaglandin E2, prostaglandin F1 $\alpha$, and interleukin- 6 in both WT and $\mathrm{TRPV}^{-/-}$mice (all $p<0.05$ ). SA decreased urine noradrenaline levels, increased afferent renal nerve activity, and improved baroreflex sensitivity in WT mice (all $p<0.05)$ but not in TRPV1 ${ }^{-/}$mice. Importantly, SA increased serum creatinine and urine kidney injury molecule- 1 levels and decreased the glomerular filtration rate in obese WT mice (all $p<0.05)$, and these detrimental effects were significantly exacerbated in obese TRPV1 ${ }^{-/-}$mice (all $p<0.05$ ). Lastly, SA treatment increased urine albumin levels in TRPV1 ${ }^{-/-}$mice $(p<0.05)$ but not in WT mice. Taken together, SA-elicited metabolic benefits and anti-inflammatory effects are independent of TRPV1, while SA-induced sympathetic suppression is dependent on TRPV1 channels. SA-induced renal dysfunction is dependent on intact TRPV1 channels. These findings suggest that SA needs to be cautiously used in patients with obesity or diabetes, as SA-induced renal dysfunction may be exacerbated due to impaired TRPV1 in obese and diabetic patients.
\end{abstract}

Keywords: TRPV1; obesity; sodium salicylate; afferent renal nerve activity; renal dysfunction; blood pressure

\section{Introduction}

Cyclooxygenase 2 (COX-2) contributes to the development of obesity and obesityassociated metabolic syndrome [1]. COX-2 is considered to be an inducible enzyme and is upregulated in inflammatory conditions $[2,3]$. Type 2 diabetes is related to COX-2-mediated inflammation [4], and inhibition of COX-2 in the diabetic rat confers renal protection [5]. Sodium salicylate (SA), a COX inhibitor, inhibits inflammation and improves insulin sensitivity and hyperleptinemia in obesity. On the other hand, COX-2-derived prostacyclin (PGI2) and prostaglandin E2 (PGE2) exert a natriuretic effect and increase renal blood flow and glomerular filtration rate (GFR) [6,7]. Renal COX-mediated generation of prostanoids is enhanced in metabolic disorders, which may play a counter-regulatory role against renal 
vasoconstriction induced by elevated renal sympathetic nerve activity (RSNA) in obesity. In addition, PGI2 is a potent vasodilator that decreases peripheral vascular resistance during the initial phase of renal hypertension [8-11]. Therefore, inhibiting COX-2 with SA could improve insulin resistance at the cost of renal function deterioration.

Understanding the action of mechanisms of COX-2 inhibitors may facilitate the development of a better COX-2-targeting treatment without the adverse effects on renal function. The transient receptor potential subfamily V member 1 (TRPV1) cation channel is expressed in renal afferent nerve fibers [12]. Activation of TRPV1 in the renal pelvis leads to an increase in ipsilateral renal afferent nerve activity (ARNA) [9-11] and a longlasting depression of efferent RSNA [13]. TRPV1 activation enhances ARNA by inducing the release of substance P (SP) from sensory nerves [11]. Increased ARNA provides an important contribution to the maintenance of low RSNA, which is essential in preventing renal sodium retention as well as the regulation of arterial pressure [11,13]. The functions of TRPV1 and ARNA are impaired in obesity [14]. Obesity is associated with an increase in RSNA [15,16] and impaired ARNA and baroreflex sensitivity (BRS) [17]. In addition, lack of TRPV1 exacerbates obesity [18]. Evidence suggests that there may be connections between COX-2 and TRPV1 [19]. It was reported that COX-2-derived PGE2 increased the release of substance P (SP) from renal pelvic sensory nerves and enhanced ARNA [20]. Therefore, the effects of COX-2 inhibitors may be mediated by TRPV1. However, it is unknown whether the metabolic and renal effects of COX-2 inhibitors are dependent on TRPV1 channels.

In the present study, we investigated whether the TRPV1 channel was involved in the metabolic and renal effects of SA treatment in diet-induced obese mice using TRPV1 gene knockout mice.

\section{Materials and Methods}

\subsection{Animals}

All experimental procedures involving animals were approved by the Institutional Animal Care and Use Committee of Michigan State University (08-17-148-00). This study followed the rules of the Declaration of Helsinki. The male TRPV1 gene knockout (TRPV1 ${ }^{-/-}$) mice (B6.129S4-TRPV1 ${ }^{\mathrm{tm} 1 J u l}$, Stock No: 003770) and matching control wild-type (WT) C57BL/6J mice (Jackson Laboratory, Bar Harbor, Maine) were used. The TRPV1-/- mice had been backcrossed to C57BL/6J mice for 10 generations. Three-week-old TRPV1-/$(n=14)$ and WT $(n=14)$ mice were fed a Western diet (WD, protein $17.3 \%$, carbohydrate $48.5 \%$, fat $21.2 \%$ (mainly from milkfat), $42 \%$ kcal from fat; 88137 , Harlan Teklad) for 4 months, during which the mice had free access to tap water. The mice were maintained with a normal $12 \mathrm{~h} / 12 \mathrm{~h}$ light/dark cycle. Room temperature was maintained at $23.0 \pm 1.0^{\circ} \mathrm{C}$, with a relative humidity between 40 and $60 \%$.The mice ( $n=7$ in each group) received either sodium salicylate $(\mathrm{SA}, 120 \mathrm{mg} / \mathrm{kg}$ body weight per day, administered by Alzet pumps, Model 2004, $1 \mathrm{~mL}$, Alzet Corporation, Palo Alto, CA, USA) or vehicle (saline, administered by the same Alzet pumps) for 4 weeks during the last 4 weeks of diet intervention. SA was purchased from Sigma-Aldrich (\#S3007, St. Louis, MO, USA) and freshly dissolved in saline before use.

\subsection{Telemetry Blood Pressure Assay}

Mean arterial pressure (MAP) and heart rate (HR) of the mice ( $n=6$ in each group) were determined using a telemetry system (Data Sciences International, St. Paul, MN, USA). In brief, the mice, after diet and SA treatment, were anesthetized with ketamine and xylazine ( 80 and $5 \mathrm{mg} / \mathrm{kg}$, i.p., respectively), and then the transmitter catheter was implanted into the left carotid artery. Mice were allowed to recovery for 7 days before ambulatory $24 \mathrm{~h}$ MAP was recorded. 


\subsection{Glucose and Insulin Tolerance Testing and Serum Leptin and Insulin Measurement}

At the end of the 16-week treatment, mice ( $n=5-7$ in each group) were fasted for $10 \mathrm{~h}$ and then given glucose ( $2 \mathrm{~g} / \mathrm{kg}$ body weight, i.p.). Tail vein blood was sampled for glucose determination using an Accu-Chek glucose meter (Roche Diagnostics, Indianapolis, IN, USA) at $0,30,60,90$, and $120 \mathrm{~min}$ after glucose administration. The areas under the curve (AUC) for glucose were calculated according to the trapezoidal rule. After $48 \mathrm{~h}$, mice were fasted for $6 \mathrm{~h}$, and then insulin ( $0.75 \mathrm{IU} / \mathrm{kg}$ body weight diluted in $0.9 \%$ saline) was injected intraperitoneally, and subsequent blood samples were taken from the tail tip. Glucose was quantified at 0, 30, 60, and $120 \mathrm{~min}$ after insulin administration using an Accu-Chek glucose meter (Roche Diagnostics). The AUC vs. time curve was calculated with the trapezoidal rule. Tail vein blood was also collected at baseline, and serum was immediately separated and stored at $-80^{\circ} \mathrm{C}$. Insulin and leptin levels were measured using a commercial kit (Crystal Chem Inc., Downers Grove, IL, USA).

\subsection{Recording of Afferent Renal Nerve Activity}

After the mice ( $n=5-7$ in each group) were anesthetized with ketamine and xylazine ( 80 and $5 \mathrm{mg} / \mathrm{kg}$, i.p., respectively), the renal nerves were isolated at the angle between the abdominal aorta and the renal artery via a left flank incision [12,21]. The nerves were placed on the bipolar, stainless-steel electrode to record multifiber nerve activity. The electrode was connected to a high-impedance probe (HIP-511, Grass Instruments). The signals were amplified 20,000× , filtered with a high-frequency cutoff at $1000 \mathrm{~Hz}$ and a low-frequency cutoff at $100 \mathrm{~Hz}$ by a Grass model P511 AC Amplifier and recorded by a Gould 2400 s recorder (Gould Instrument System, Valley View, OH, USA). After the renal nerve activity was verified using its pulse synchronous rhythmicity with the heartbeat, the nerves were sectioned, and ARNA was recorded from the distal cut end of a renal nerve branch. The electrode was fixed to the renal nerve with Kwik-Cast \& Kwik-Sil (World Precision Instruments, Sarasota, FL, USA). The experiment started after the placement of nerve electrodes and physiological stabilization for $60 \mathrm{~min}$. Two MD-2000 microdialysis tubes (ID 0.18/OD $0.22 \mathrm{~mm}$; BASi) were bonded together and placed inside the left ureter via a midline incision. One of the tubes, of which the tip extended 1 to $2 \mathrm{~mm}$ further into the renal pelvis compared with the other, was used for drug perfusion, whereas the other was used for urine draining. The perfusion was performed at a rate of $10 \mu \mathrm{L} / \mathrm{min}$. Capsaicin $\left(10^{-6} \mathrm{mmol} / \mathrm{L}\right)$ was perfused into the renal pelvis in 3-min periods, and the recovery value of renal nerve activity was recorded $10 \mathrm{~min}$ after the treatment. The postmortem renal nerve activity recorded as the background signal of renal nerve activity was subtracted from all of the nerve activity recording values. Capsaicin-stimulated renal nerve activity was expressed as a percentage of its baseline value prior to the application of capsaicin.

\subsection{Determination of Baroreflex Function}

The baroreflex function of the mice ( $n=5-7$ in each group) was evaluated by measuring the reflex changes in RSNA and HR in response to decreases and increases in MAP induced by intravenous infusion of $50 \mu \mathrm{g} / \mathrm{mL}$ sodium nitroprusside (SNP) and $125 \mu \mathrm{g} / \mathrm{mL}$ phenylephrine (PE), respectively. SNP and PE were administered via the jugular vein in successive ramped infusions at an initial rate of $5 \mu \mathrm{L} / \mathrm{min}$, increased by $5 \mu \mathrm{L} / \mathrm{min}$ every $30 \mathrm{~s}$ [22]. The PE and SNP infusions were done separately, with one drug administered after the blood pressure response to the other drug had returned to baseline level, and the order of drugs was administered randomly. Infusions were stopped if MAP reached a minimum of $60 \mathrm{mmHg}$ or a maximum of $140 \mathrm{mmHg}$. The RSNA was recorded from the proximal cut end of a renal nerve and hooked up to electrodes. The postmortem renal nerve activity recorded as the background of renal nerve activity was subtracted from all of the values. Baroreflex-mediated changes in RSNA were expressed as a percentage of its baseline value. Baroreflex modulation of RSNA and HR was estimated by calculating (1) the percent change in integrated activity and (2) the change in HR in relation to the change in mean BP induced by PE and SNP. 


\subsection{Renal Blood Flow Recording}

Anesthesia was induced with $5 \%$ isoflurane (Abbott Laboratories, Chicago, IL, USA) and maintained with $1 \%$ isoflurane, and the mice ( $n=5-7$ in each group) were placed on a heating pad to maintain body temperature at $37^{\circ} \mathrm{C}[23,24]$. After surgical preparation, the kidney was placed in a clay cup without exerting tension on the renal vessels. The left jugular vein was cannulated for injections and infusion of a $0.9 \%$ sodium chloride solution containing $1 \%$ bovine serum albumin at a rate of $0.2 \mathrm{~mL} / \mathrm{Kg} / \mathrm{min}$ throughout the experiment. Cortical and medullary blood flows (CBF and MBF, respectively) were measured simultaneously by a dual-channel, laser-Doppler flowmeter (Periflux 5000, Perimed, North Royalton, OH, USA). For measurement of CBF, the probe was placed perpendicular to the surface of the cortex and MBF was measured by a probe inserted into the outer medulla at a depth of 3-4 $\mathrm{mm}$. The position of the probe in the outer medulla was verified at the end of each experiment by dissection of the kidney. The experiment started after the placement of the probe and physiological stabilization for $60 \mathrm{~min}$ to obtain baseline recordings of CBF and MBF. Next, the mice received intravenous bolus $(10 \mu \mathrm{L})$ injections of angiotensin II (Ang II, Sigma) at doses of 0.5, 2.5, and $12.5 \mathrm{ng} / \mathrm{kg}$. Consecutive administrations of Ang II were separated by a period of $10 \mathrm{~min}$ to allow a full recovery of hemodynamic variables. Electrical signals of both probes were digitized and recorded in real time and analyzed by Perisoft for Windows software (Perimed).

\subsection{Renal NF- $\kappa B$ p65 Activity Assay}

Nuclear protein was extracted from the kidney with a nuclear extract kit (Active Motif, Carlsbad, CA, USA) based on the manufacturer's instructions. The binding activities of free NF- $\kappa B$ p65 in nuclear extracts were determined with the use of the TransAM NF- $k B$ p65 assay kit (Active Motif) following the manufacturer's protocol. The plate was read at $450 \mathrm{~nm}$ using an absorbance microplate reader (Molecular Devices, Sunnyvale, CA, USA).

\subsection{Plasma and Urine Analysis}

At the end of the 16-week treatment, mice were placed in mouse metabolic cages for $24 \mathrm{~h}$ urine collection. Urine samples were centrifuged and stored at $-80^{\circ} \mathrm{C}$. Urinary albumin and noradrenaline were measured with enzyme-linked immunosorbent assay (ELISA) kits (Mouse Albumin ELISA, \#1011, Exocell, Philadelphia, PA, USA; Norepinephrine ELISA Kit, \#E4360, Biovision, Milpitas, CA, USA). Urinary kidney injury molecule-1 (KIM-1) as a marker of renal injury was quantified using a mouse kim-1 Elisa kit (CL0880, Cell applications Inc, CA, USA) according to the manufacturer's protocol. Plasma creatinine concentrations were assayed using the Creatinine Colorimetric/Fluorometric Assay Kit (K625, Biovision, Milpitas, CA, USA). Endogenous creatinine clearance is a sensitive and accurate method for assessing glomerular filtration rate (GFR). Plasma and urine creatinine levels were determined using the above-mentioned assay kit (K625, Biovision) and calculation of creatinine clearance: GFR $=\mathrm{U}[\mathrm{Cr}] \times$ Volume $] / \mathrm{P}[\mathrm{Cr}] \times[$ Time] [25]. Since the half-life of PGI2 was short, 6-keto-PGFla, its stable and inactive metabolite, was measured. A PGE2 EIA Kit-Monoclonal (\#514010, Cayman Chemical Company, MI, USA) and a 6-keto-PGFla EIA Kit (\#515211, Cayman Chemical Company, MI, USA) were used according to the manufacturer's instructions.

\subsection{Statistical Analysis}

All values are expressed as mean \pm SEM. Differences among groups were performed by two-way ANOVA analysis followed by the Tukey-Kramer multiple comparison test. The results were considered statistically significant at $p<0.05$.

\section{Results}

\subsection{Effects of $S A$ on Blood Pressure}

Ambulatory blood pressure was measured by telemetry after the mice had been fed with WD for 16 weeks and treated with SA or vehicle for 4 weeks (Figure 1A). SA treatment 
did not change the $24 \mathrm{~h}$ MAP of WD-fed WT mice but significantly increased MAP in WD-fed TRPV1 ${ }^{-1-}$ mice compared with WD-fed TRPV1 $1^{-/-}$mice treated without SA $(p<0.05$, Figure 1B). SA treatment had no significant effects on body weight of either WT or TRPV1 ${ }^{-/-}$mice (WT-WD, $47.1 \pm 3.4 \mathrm{~g}$; WT-WD-SA, $41.6 \pm 3.2 \mathrm{~g}$; TRPV1 ${ }^{-/-}-\mathrm{WD}$, $46.2 \pm 3.7 \mathrm{~g} ; \mathrm{TRPV}^{-/-}$-WD-SA, $46.0 \pm 2.9 \mathrm{~g}$ ).

A

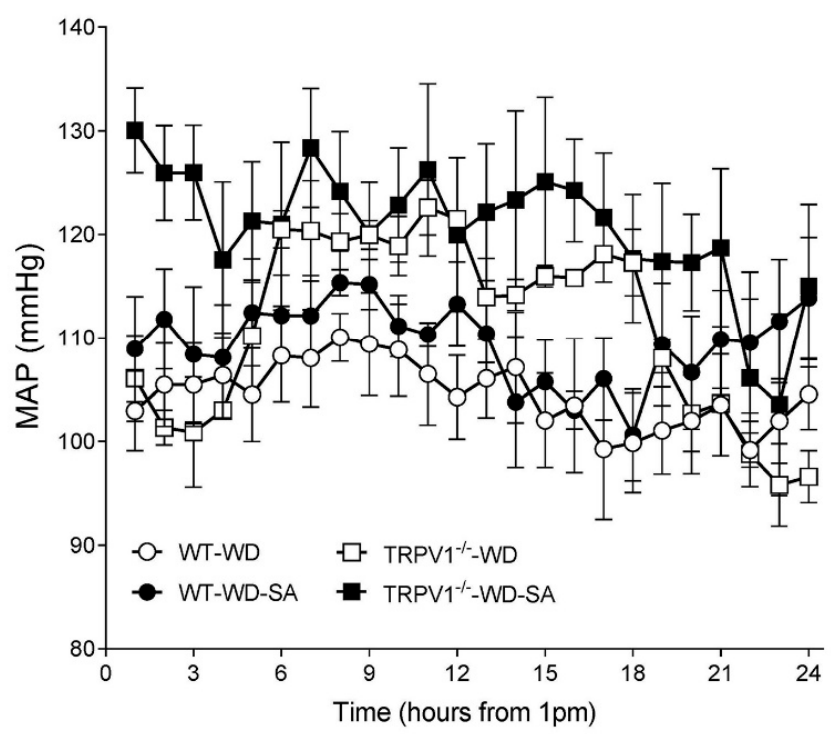

B

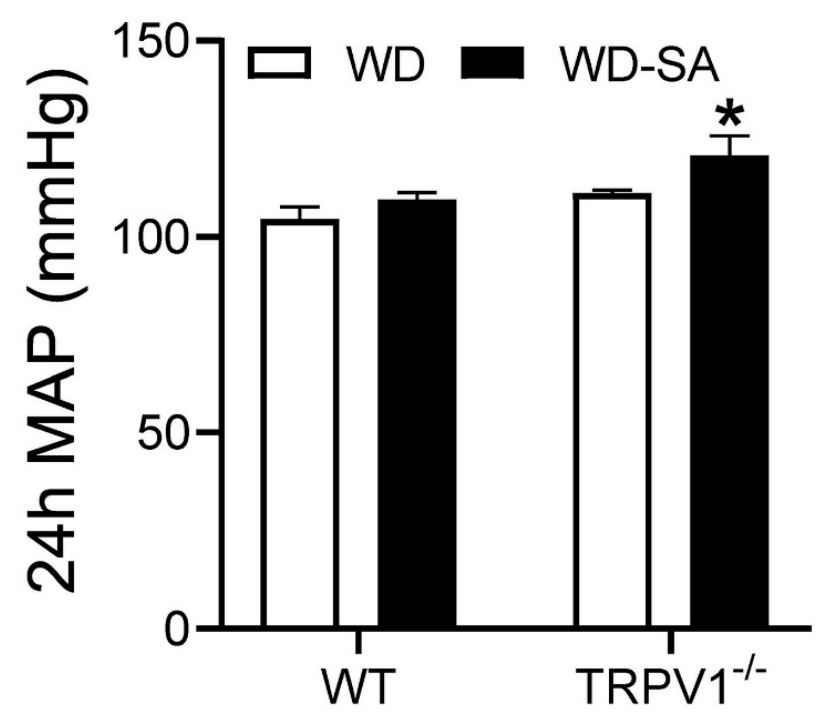

Figure 1. SA treatment-induced hypertension in obese TRPV1 $1^{-/-}$mice. Telemetric recording of ambulatory blood pressure (A) and 24-h mean arterial pressure (MAP) (B) in WD-fed WT mice and TRPV1 ${ }^{-/}$- mice treated with or without SA. Differences among groups were performed by two-way ANOVA analysis followed by the Tukey-Kramer multiple comparison test. Values are mean $\pm \mathrm{SEM} ; n=5-6$; $^{*} p<0.05$ vs. TRPV1 ${ }^{-/-}$mice treated without SA.

\subsection{Effects of SA on Glucose Tolerance and Insulin Resistance}

Glucose tolerance, reflected as the AUC of the glucose tolerance test, was significantly improved by treatment with SA in both WT and TRPV1 ${ }^{-/}$mice (Figure $2 \mathrm{~A}$, both $p<0.05$ ). Moreover, glucose tolerance was impaired in TRPV1 ${ }^{-/-}$mice compared with WT mice, independent of SA treatment (Figure 2A, both $p<0.05$ ). The AUC for the insulin tolerance test was reduced in the SA-treated groups for both WT and TRPV1 ${ }^{-1-}$ mice (Figure 2B, both $p<0.05)$. Fasting insulin and leptin concentrations were lower in both strains with SA vs. vehicle treatment (Figure $2 \mathrm{C}, \mathrm{D}$, all $p<0.05$ ). There were no differences in insulin and leptin levels between WT and TRPV1 ${ }^{-/-}$mice despite treatment with SA.

\subsection{Effects of SA on Autonomic Nerve Activity}

SA treatment significantly decreased urinary noradrenaline in WD-fed WT mice, while it increased it in WD-fed TRPV1 ${ }^{-/-}$mice (Figure 3A, both $p<0.05$ ). Capsaicin, a TRPV1 agonist, was perfused into the renal pelvis, which stimulated ARNA in WT mice but not in TRPV1 ${ }^{-/-}$mice (Figure 3B). The capsaicin-induced increase in ipsilateral ARNA was enhanced by SA treatment in WD-fed WT mice (Figure $3 B, p<0.05$ ). These results suggest that SA treatment suppressed RSNA and improved ARNA, likely through TRPV1.

\subsection{Effects of SA Treatment on Baroreflex Sensitivity}

Baroreflex sensitivity was evaluated by measuring the changes of HR and RSNA in response to phenylephrine- and nitroprusside-induced increase and decrease of MAP, respectively. The baroreflex sensitivity was improved with SA vs. vehicle treatment in WD-fed WT mice, but not in WD-fed TRPV1 ${ }^{-/-}$mice (Figure 4). These results suggest that SA improved baroreflex sensitivity, which was dependent on intact TRPV1 channels. 
A

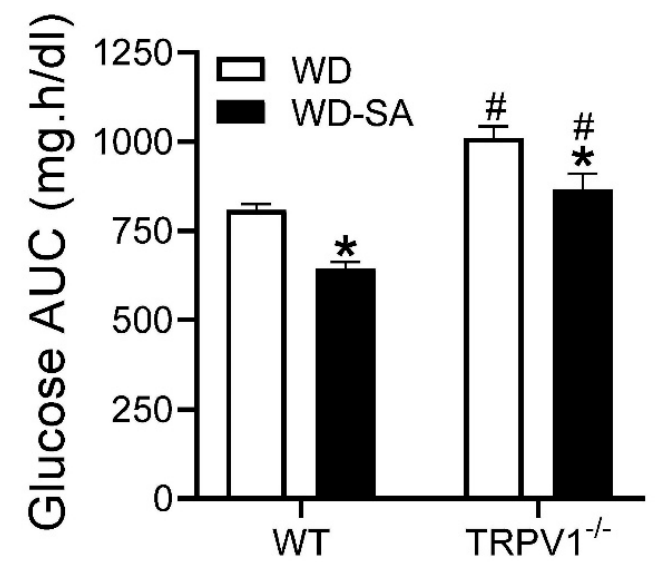

C

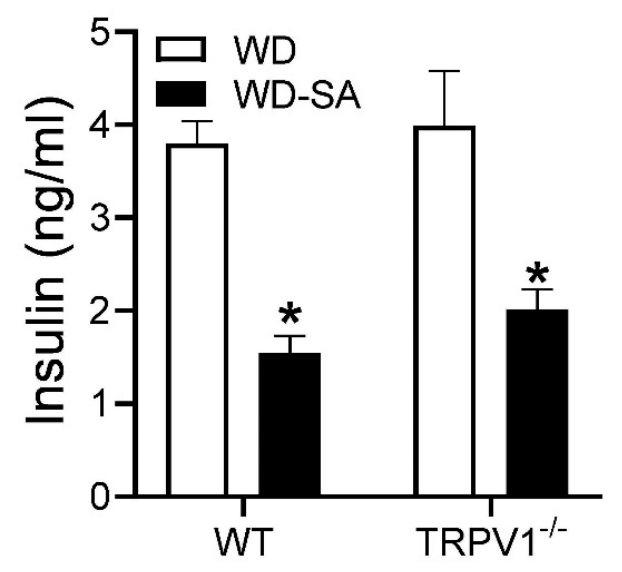

$\mathrm{B}$

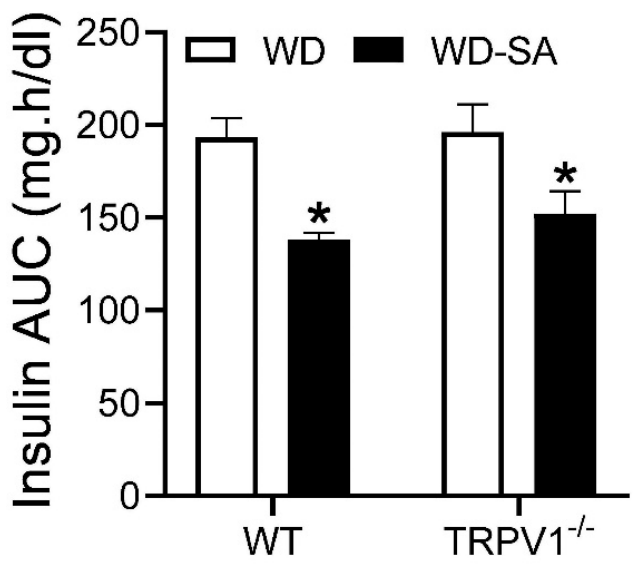

D

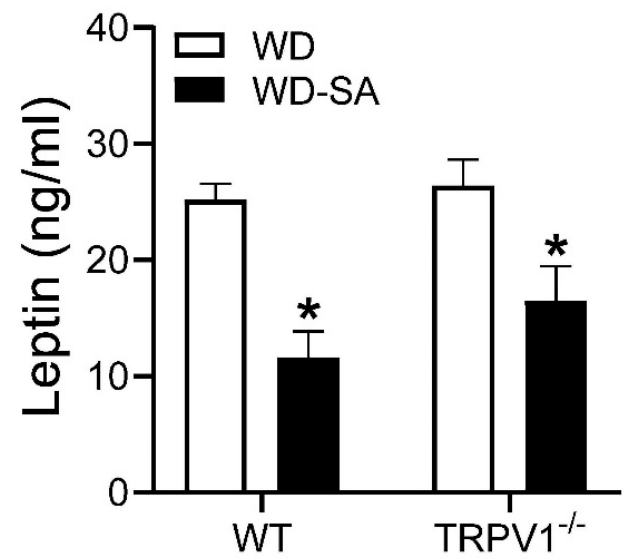

Figure 2. Effects of SA on glucose tolerance and insulin resistance. Area under the curve (AUC) of the insulin tolerance test (A) and glucose tolerance test (B) in WD-fed WT mice and TRPV1 ${ }^{-/-}$mice treated with or without SA. Plasma insulin (C) and leptin (D) levels of WD-fed WT mice and TRPV1 ${ }^{-/-}$mice treated with or without SA. Differences among groups were performed by two-way ANOVA analysis followed by the Tukey-Kramer multiple comparison test. Values are mean \pm SEM; $n=6-7 ;{ }^{*} p<0.05$ vs. isogenic mice treated without SA; $p<0.05$ vs. WT mice with the same treatment.

A

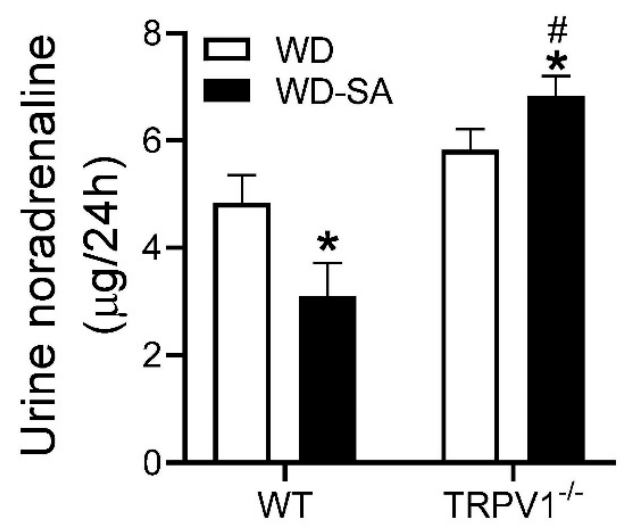

B

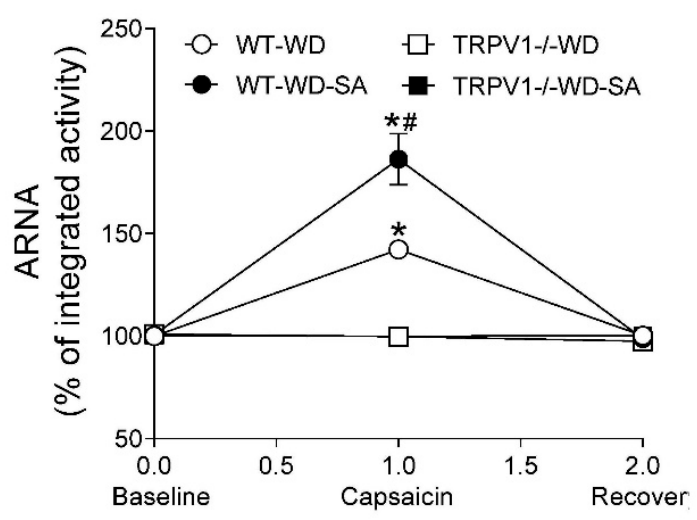

Figure 3. Effects of SA on autonomic nerve activity. (A) Urinary norepinephrine levels of WD-fed WT mice and TRPV1 ${ }^{-/-}$ mice treated with or without SA. (B) Intra-renal pelvic infusion of capsaicin-induced afferent renal nerve activity (ARNA). Differences among groups were performed by two-way ANOVA analysis followed by the Tukey-Kramer multiple comparison test. Values are mean $\pm \mathrm{SEM} ; n=6-7 ;{ }^{*} p<0.05$ vs. isogenic mice treated without SA; ${ }^{\#} p<0.05$ vs. WT mice with the same treatment. 
A

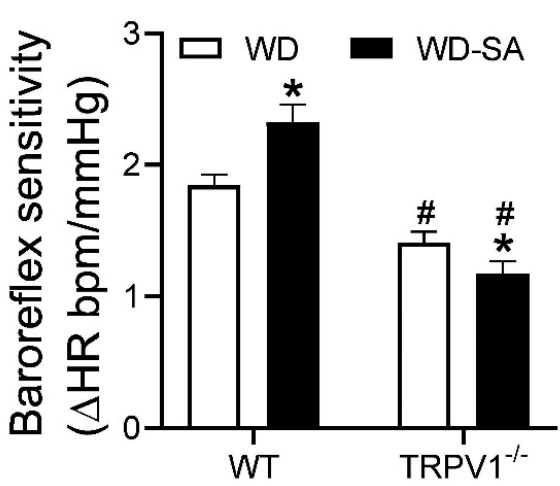

C

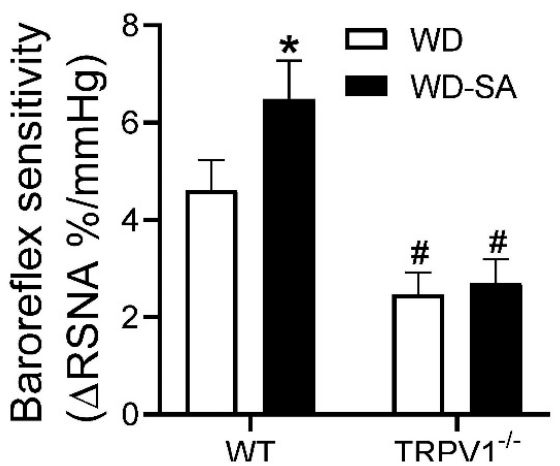

B
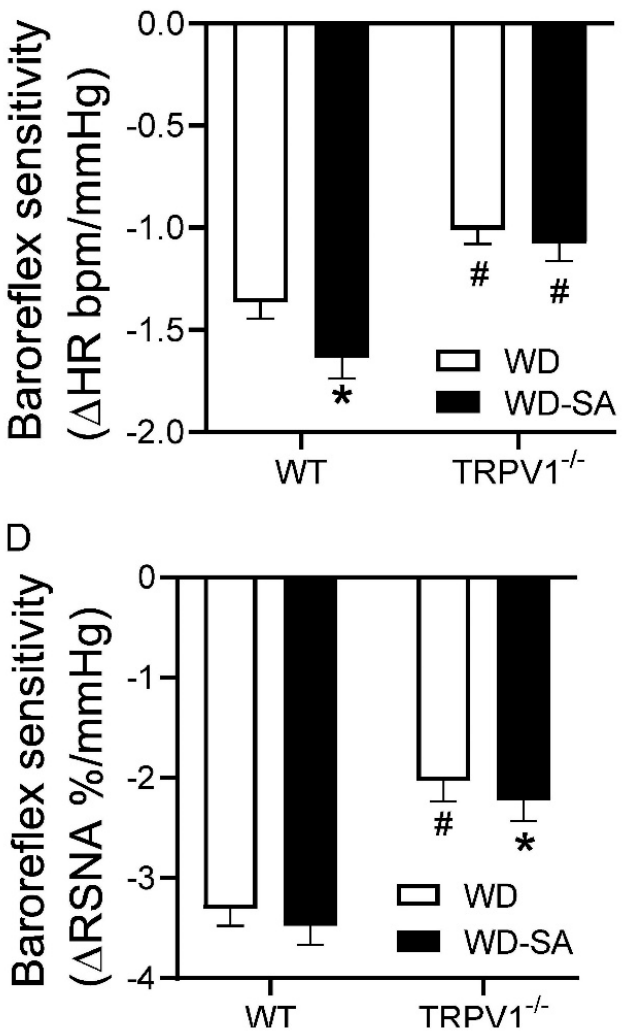

Figure 4. Effects of SA treatment on baroreflex sensitivity. Baroreflex sensitivity of heart rate (HR) in response to intravenous injection of sodium nitroprusside $(50 \mu \mathrm{g} / \mathrm{mL})(\mathbf{A})$ and phenylephrine $(125 \mu \mathrm{g} / \mathrm{mL})(\mathbf{B})$ in WD-fed WT mice and TRPV1 ${ }^{-/-}$mice treated with or without SA. Baroreflex sensitivity of RSNA in response to intravenous injection of sodium nitroprusside $(50 \mu \mathrm{g} / \mathrm{mL})(\mathbf{C})$ and phenylephrine $(125 \mu \mathrm{g} / \mathrm{mL})(\mathrm{D})$ in WD-fed WT mice and TRPV1 ${ }^{-/-}$mice treated with or without SA. Differences among groups were performed by two-way ANOVA analysis followed by the Tukey-Kramer multiple comparison test. Values are mean $\pm \mathrm{SEM} ; n=5-7 ;{ }^{*} p<0.05$ vs. isogenic mice treated without SA; ${ }^{\#} p<0.05$ vs. WT mice with the same treatment.

\subsection{Effects of $S A$ on Renal Blood Flow}

Infusions of Ang II (0.5 to $12.5 \mathrm{ng} / \mathrm{Kg}$, i.v.) dose-dependently reduced $\mathrm{CBF}$, and a further decrease was observed in the WD-fed TRPV1 ${ }^{-1-}$ mice compared with WD-fed WT mice (Figure 5A). SA treatment had no significant effects on CBF in either WT or TRPV1 ${ }^{-/-}$ mice (Figure 5A). Infusions of Ang II dose-dependently increased MBF in WD-fed WT mice, while they significantly decreased MBF in WD-fed TRPV1 ${ }^{-/-}$mice (Figure $5 \mathrm{~B}$ ), indicating TRPV1 ablation abolished the response of CBF and MBF to Ang II infusion in mice fed WD. Moreover, SA decreased the response of MBF to Ang II infusion in WD-fed TRPV1-/mice compared to WD-fed WT mice.

\subsection{Effects of SA on Renal Inflammatory Markers}

SA treatment significantly decreased the binding activity of renal NF- $\mathrm{KB}$ p65 and urine PGE2 and PGF1 $\alpha$ levels in both WD-fed WT and WD-fed TRPV1 ${ }^{-/-}$mice (Figure $6 \mathrm{~A}-\mathrm{C}$, all $p<0.05)$. SA lowered urine Il-6 levels in WD-fed WT mice $(p<0.05)$ but not in WD-fed TRPV1 ${ }^{-1-}$ mice (Figure 6D). In addition, WD-fed TRPV1 ${ }^{-/-}$mice had higher renal NF- $\kappa \mathrm{B}$ p65 binding activity and urine PGF1 $\alpha$ and IL-6 levels than WD-fed WT mice (Figure 6A,C,D, all $p<0.05$ ). 
A

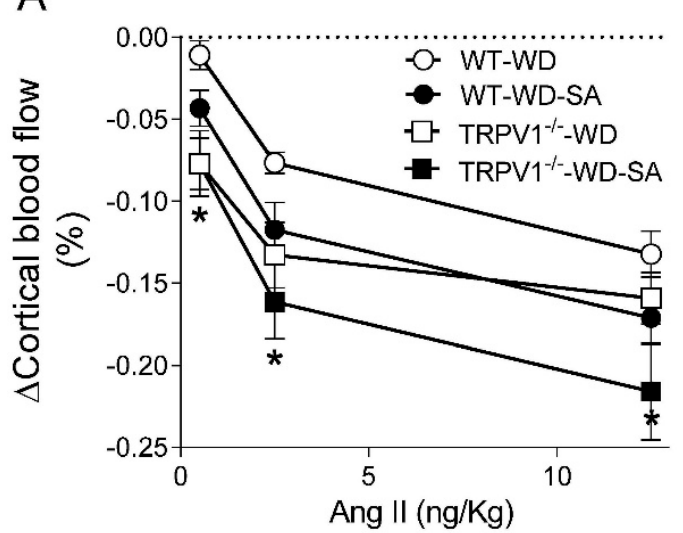

B

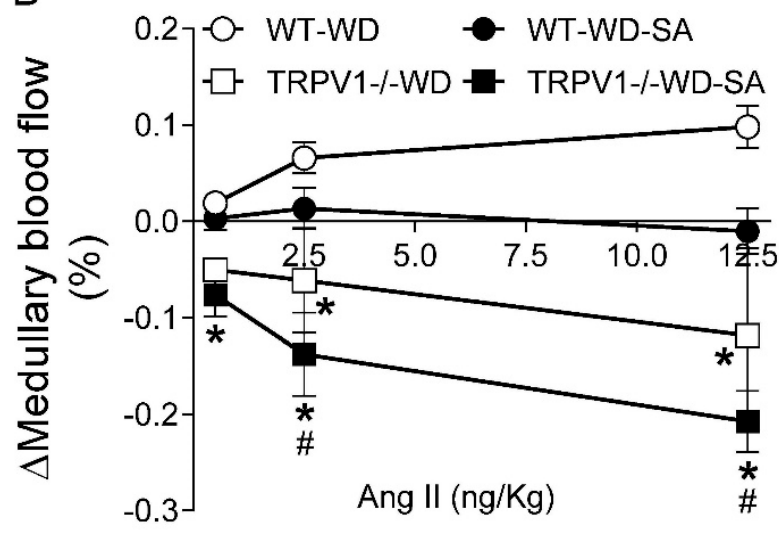

Figure 5. Effects of SA on renal blood flow. Peak changes of mean renal cortical blood flow (CBF) (A) and medullary blood flow (MBF) (B) in response to intravenous bolus injections of angiotensin II (Ang II) at doses of 0.5, 2.5, and 12.5 ng/ $\mathrm{kg}$ in WD-fed WT mice and TRPV1 ${ }^{-/-}$mice treated with or without SA. Differences among groups were performed by two-way ANOVA analysis followed by the Tukey-Kramer multiple comparison test. Values are mean \pm SEM; $n=5-7 ;{ }^{*} p<0.05$ vs. isogenic mice treated without SA; ${ }^{*} p<0.05$ vs. WT mice with the same treatment.

A

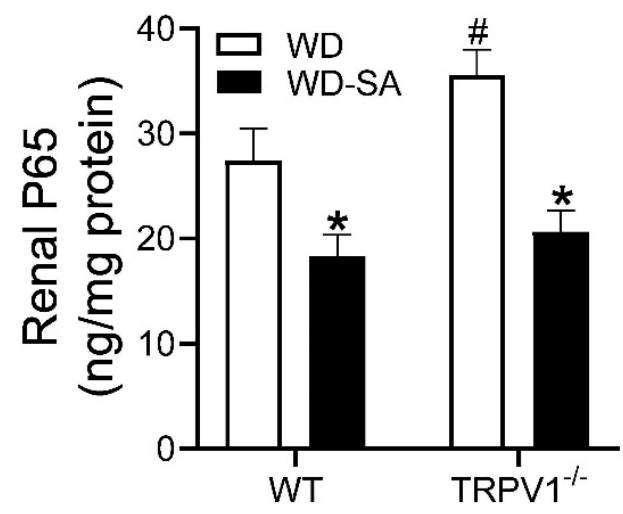

C

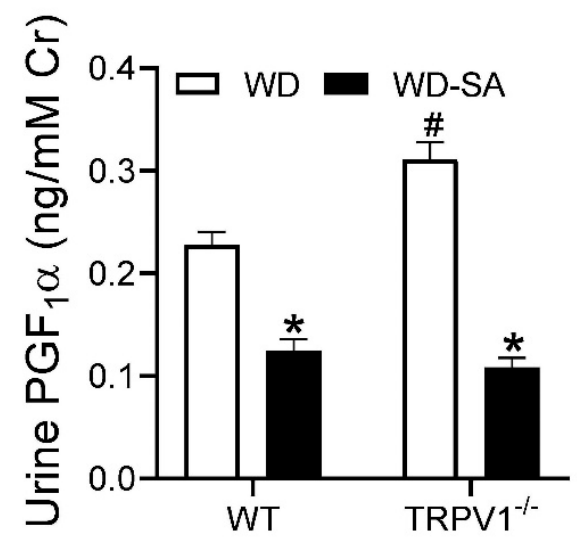

B

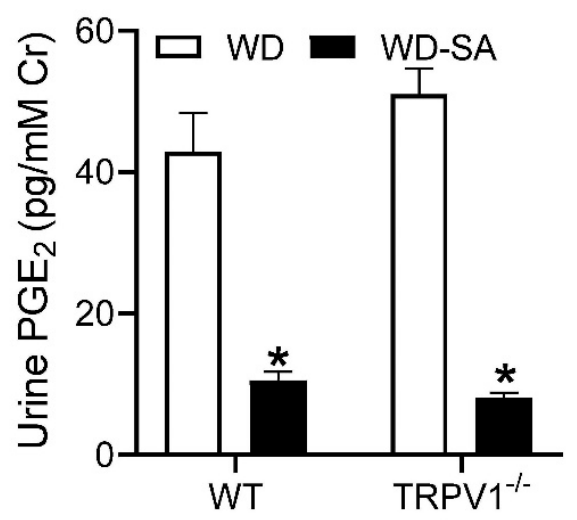

D

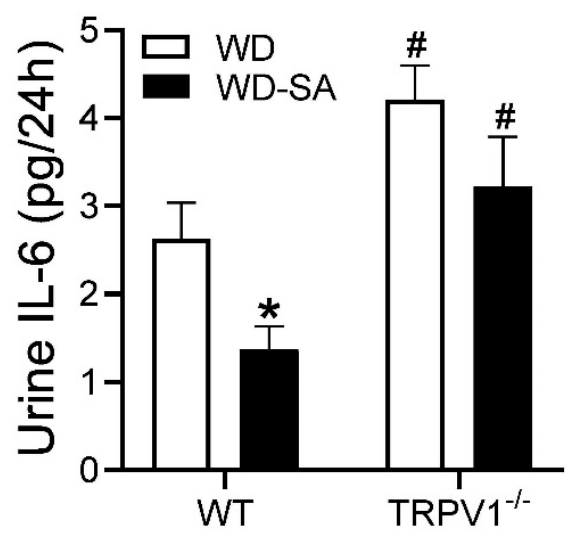

Figure 6. Effects of SA on renal inflammatory markers. Renal p65 binding activity (A), urine PGE2 (B), PGF1 $\alpha$ (C), and IL-6 (D) in WD-fed WT mice and TRPV1 ${ }^{-/-}$mice treated with or without SA. Differences among groups were performed by two-way ANOVA analysis followed by the Tukey-Kramer multiple comparison test. Values are mean $\pm \mathrm{SEM} ; n=5-7$; ${ }^{*} p<0.05$ vs. isogenic mice treated without SA; $p<0.05$ vs. WT mice with the same treatment. 


\subsection{Effects of SA on Renal Function}

SA treatment decreased GFR and increased plasma creatinine and urine Kim-1 levels in both WD-fed WT and TRPV1 ${ }^{-/}-$mice (Figure 7A-C, all $p<0.05$ ), to a greater magnitude in TRPV1 ${ }^{-1-}$ mice than in WT mice (Figure 7A-C, all $p<0.05$ ). SA increased urinary albumin levels in WD-fed TRPV1 ${ }^{-/}$- mice but not in WD-fed WT mice (Figure 7D, $p<0.05$ ). Urinary Kim-1 and albumin levels in WD-fed TRPV1 ${ }^{-/}$mice were higher than those in WT mice fed with WD (Figure $7 C, D, p<0.05$ ). These results indicate that SA caused more significant renal dysfunction in TRPV1 ${ }^{-/-}$mice than in WT mice.

A

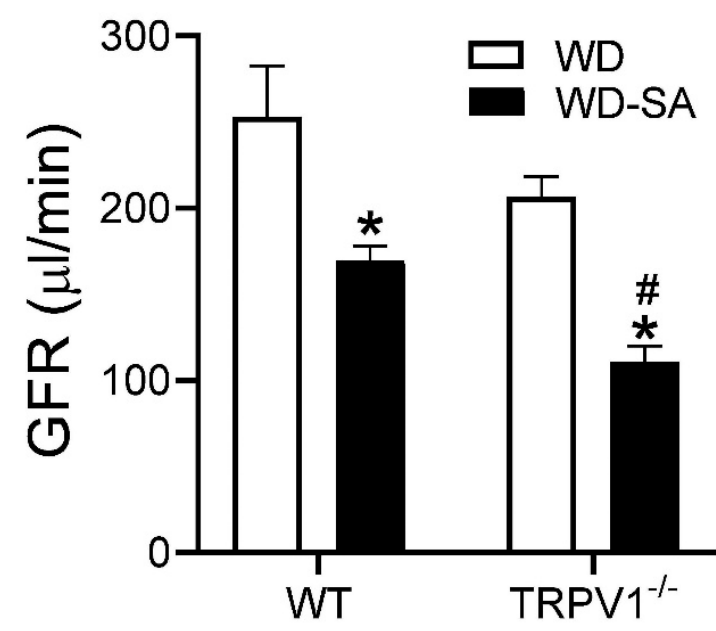

C

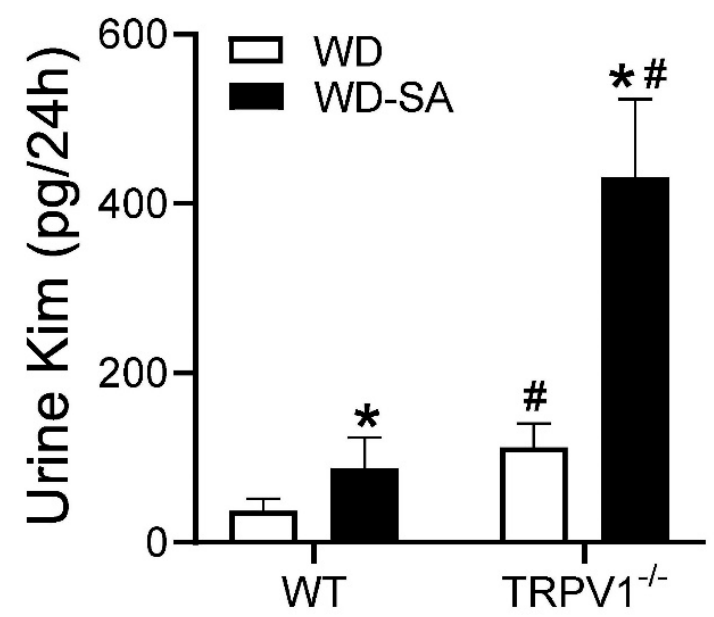

B

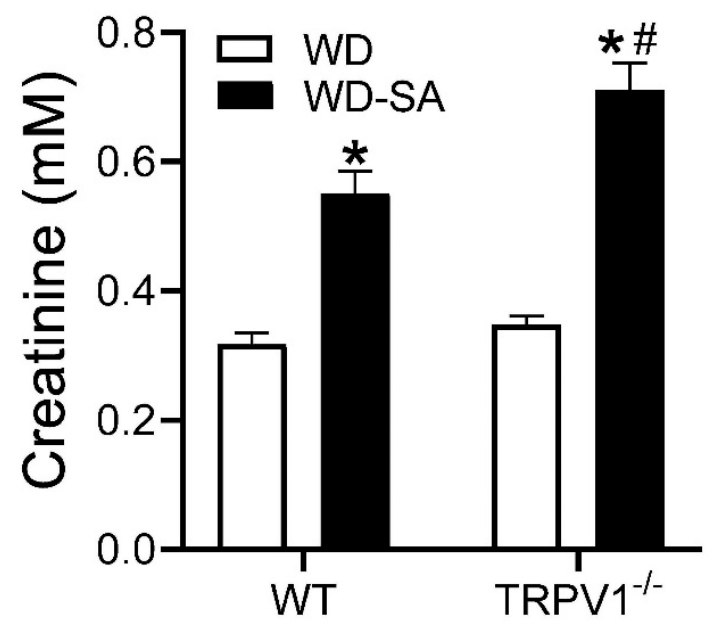

$\mathrm{D}$

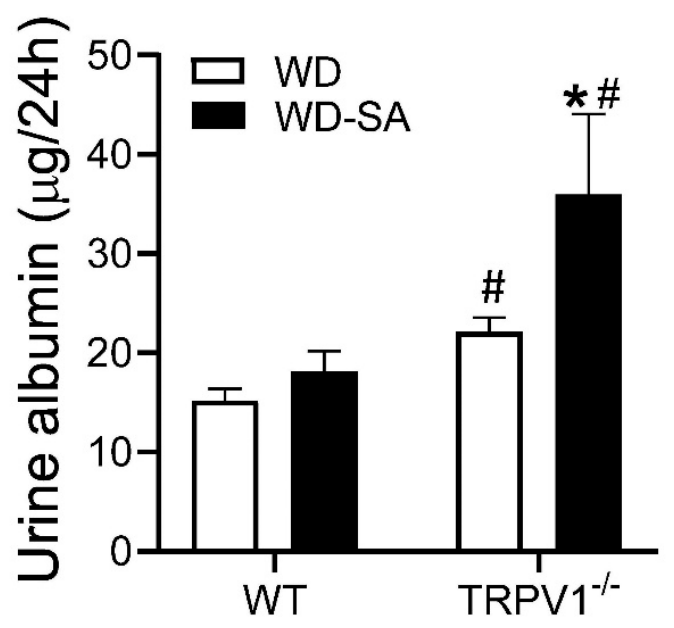

Figure 7. Effects of SA on renal function. GFR (A), serum creatinine (B), urine Kim-1 (C), and urine albumin (D) in WD-fed WT mice and TRPV1 ${ }^{-/-}$mice treated with or without SA. Differences among groups were performed by two-way ANOVA analysis followed by the Tukey-Kramer multiple comparison test. Values are mean $\pm \mathrm{SEM} ; n=5-7 ;{ }^{*} p<0.05$ vs. isogenic mice treated without SA; ${ }^{\#} p<0.05$ vs. WT mice with the same treatment.

\section{Discussion}

There are three main findings in the present study. Firstly, SA treatment attenuated renal inflammation and improved insulin resistance in both obese WT and TRPV1 ${ }^{-1-}$ mice, indicating that the beneficial effects of SA on insulin sensitivity are independent of TRPV1. Secondly, SA treatment suppressed RSNA, increased ARNA, and improved baroreflex sensitivity in obese WT mice but not in obese TRPV1 ${ }^{-/}$mice, suggesting the nerveprotecting effects of SA were dependent on TRPV1. Thirdly, SA treatment caused renal 
dysfunction in obese WT mice, and this detrimental effect was exacerbated in TRPV1-/mice, indicating that SA-induced renal dysfunction was dependent on whether TRPV1 channels were intact.

Activation of TRPV1 expressed in afferent sensory nerve fibers leads to an increase in ARNA [10]. Increased ARNA contributes to the maintenance of a low efferent RSNA, which is essential in preventing renal sodium retention and the regulation of arterial pressure $[11,13]$. The function of sensory nerves, especially TRPV1-positive nerves, is impaired in obesity. Obesity decreased capsaicin-induced transmitter release from sensory nerves [14]. Previous studies showed that TRPV1 were expressed throughout the entire baroreceptive afferent pathway, and TRPV1 ablation impaired the baroreflex control of efferent RSNA and HR [22]. The baroreceptor dysfunction is an initial change in obesity, which is followed by sympathetic overactivation and hypertension [17]. TRPV1 ${ }^{-/-}$mice fed with WD had increased urinary Kim-1 and albumin levels compared with WD-fed WT mice, indicating a reno-protective role of TRPV1 in obese mice. The present study demonstrated that SA treatment suppressed RSNA, increased ARNA, and improved baroreflex sensitivity in obese WT mice, likely through TRPV1. Renal afferent nerves could be damaged and afferent nerve activity impaired by inflammation in obesity [26,27]. SA may increase ARNA through its anti-inflammatory effects.

SA reverses hyperglycemia, hyperinsulinemia, and hyperleptinemia in WD-induced obese mice [28-31]. The present study demonstrated that SA treatment decreased plasma insulin, glucose, and leptin levels in obese WT mice as well as in obese TRPV1 ${ }^{-/-}$mice. These results suggest that the metabolic benefits of SA are probably not mediated by its nerve-protective effects, as the latter is dependent on intact TRPV1 channels. Leptin is an important factor driving obesity-associated arterial hypertension. Leptin-induced increases in RSNA can be suppressed by baroreflex activation [32]. Impaired baroreflex leads to increased RSNA and hypertension in patients with type 2 diabetes [33-35]. Therefore, it is possible that the nerve-protective effects of SA are mediated by its effects on leptin levels. It is worth mentioning that SA may exert vasodilatory effects and acutely lower blood pressure in hypertensive rats [36]. In the present study, the long-term blood pressure raising effects of SA were more likely due to its action on the kidney.

COX enzymatic products can have antihypertensive and prohypertensive properties, depending on the profile of prostanoids produced [37]. Long-term use of non-steroidal antiinflammatory drugs and COX-2 inhibitors increased arterial blood pressure and induced edema and congestive heart failure in a significant proportion of patients [37]. SA inhibits COX, leading to increased metabolism of arachidonic acid via lipoxygenase (LOX) and cytochrome P450 (CYP) pathways. Products of the LOX pathway, 12- and 15-(S)-HPETE and 5- and 15-(S)-HETEs, can directly activate TRPV1 [38]. TRPV1 activation improves endothelial function, increases endothelium nitric oxide (NO) production, improves vasorelaxation, and may prevent hypertension [39]. Moreover, NO can also reduce RSNA [40], which might contribute to the increase in renal blood flow. However, SA treatment in TRPV1 $1^{-/-}$ mice might lose these beneficial effects and cause further impairment on renal function.

SA suppressed urinary 6-keto PGF1 $\alpha$ and PGE2 in obese WT and TRPV1 ${ }^{-/-}$mice, which might be related to a further increase in RSNA and elevation of blood pressure in obese TRPV1 ${ }^{-/}$mice. COX-2 inhibitors prevent inflammatory response via inhibition of PG synthesis, which may also lead to blood pressure elevation, as PGE2 and PGI2 are important vasodilators. In response to WD feeding, the kidney increases synthesis of PGI2 and PGE2, which may be more pronounced in WD-fed TRPV1 ${ }^{-/-}$mice because TRPV1 ablation may decrease NO production [39] and other vasodilators such as calcitonin gene-related peptide (CGRP) and SP release. The present study showed that TRPV1 ablation increased urinary levels of 6-keto PGF1 $\alpha$, a major metabolite of PGI2 in obese TRPV1 ${ }^{-/-}$mice. PGI2 and PGE2 can activate and sensitize TRPV1 and increase SP and CGRP release [26,27], and these effects are absent in TRPV1 ${ }^{-/-}$mice. Taken together, SA treatment in obese TRPV1 ${ }^{-1-}$ mice further decreased the release of vasodilators including SP, CGRP, PGE2, and PGI2, which might contribute to elevation of blood pressure and 
deterioration of renal function. SA-induced renal dysfunction in obese mice is dependent on whether the TRPV1 channels are intact.

Taken together, our data suggest that the inhibition of COX with SA in mice fed a WD diet increases ARNA and improves baroreflex control of sympathetic activity. SAmediated nerve protective effects are abolished when TRPV1 is ablated, accompanied by exacerbated renal functional impairment and elevated blood pressure. These data may have significant clinical implications for obese and diabetic patients with impaired TRPV1 that may contribute to the development of resistant hypertension in these patients when treated with nonsteroidal anti-inflammatory drugs.

Author Contributions: Conception and design of the study: D.H.W.; Acquisition and analysis of data: B.Z.; Statistical analysis: B.Z.; Interpretation of data: B.Z., S.M. and D.H.W.; Drafting the manuscript: B.Z.; Revising the manuscript: S.M. and D.H.W.; All authors have read and agreed to the published version of the manuscript.

Funding: This study was supported in part by an National Institute of Health grant: DK67620 to D.H.W.

Institutional Review Board Statement: All experimental procedures involving animals were approved by the Institutional Animal Care and Use Committee of Michigan State University.

Informed Consent Statement: Not applicable.

Data Availability Statement: All data are included in the paper.

Conflicts of Interest: The authors declare no conflict of interest

\section{References}

1. Danneskiold-Samsoe, N.B.; Sonne, S.B.; Larsen, J.M.; Hansen, A.N.; Fjaere, E.; Isidor, M.S.; Petersen, S.; Henningsen, J.; Severi, I.; Sartini, L.; et al. Overexpression of cyclooxygenase-2 in adipocytes reduces fat accumulation in inguinal white adipose tissue and hepatic steatosis in high-fat fed mice. Sci. Rep. 2019, 9, 8979. [CrossRef] [PubMed]

2. Davidge, S.T. Prostaglandin H synthase and vascular function. Circ. Res. 2001, 89, 650-660. [CrossRef] [PubMed]

3. Harris, R.C.; McKanna, J.A.; Akai, Y.; Jacobson, H.R.; Dubois, R.N.; Breyer, M.D. Cyclooxygenase-2 is associated with the macula densa of rat kidney and increases with salt restriction. J. Clin. Investig. 1994, 94, 2504-2510. [CrossRef] [PubMed]

4. Helmersson, J.; Vessby, B.; Larsson, A.; Basu, S. Association of type 2 diabetes with cyclooxygenase-mediated inflammation and oxidative stress in an elderly population. Circulation 2004, 109, 1729-1734. [CrossRef] [PubMed]

5. Quilley, J.; Santos, M.; Pedraza, P. Renal protective effect of chronic inhibition of COX-2 with SC-58236 in streptozotocin-diabetic rats. Am. J. Physiol. 2011, 300, H2316-H2322. [CrossRef]

6. Gullner, H.G.; Nicolaou, K.C.; Bartter, F.C.; Kelly, G. Effect of prostacyclin (PGI2) on renal function and renin secretion in hypophysectomized dogs. Nephron 1980, 25, 283-287. [CrossRef]

7. Villa, E.; Garcia-Robles, R.; Haas, J.; Romero, J.C. Comparative effect of PGE2 and PGI2 on renal function. Hypertension 1997, 30, 664-666. [CrossRef]

8. Morera, S.; Santoro, F.M.; Roson, M.I.; de la Riva, I.J. Prostacyclin (PGI2) synthesis in the vascular wall of rats with bilateral renal artery stenosis. Hypertension 1983, 5, V38-V42. [CrossRef]

9. Zhu, Y.; Wang, Y.; Wang, D.H. Diuresis and natriuresis caused by activation of VR1-positive sensory nerves in renal pelvis of rats. Hypertension 2005, 46, 992-997. [CrossRef]

10. Xie, C.; Sachs, J.R.; Wang, D.H. Interdependent regulation of afferent renal nerve activity and renal function: Role of transient receptor potential vanilloid type 1 , neurokinin 1, and calcitonin gene-related peptide receptors. J. Pharm. Exp. Ther. 2008, 325, 751-757. [CrossRef]

11. Kopp, U.C.; Jones, S.Y.; DiBona, G.F. Afferent renal denervation impairs baroreflex control of efferent renal sympathetic nerve activity. Am. J. Physiol Regul Integr Comp. Physiol. 2008, 295, R1882-R1890. [CrossRef] [PubMed]

12. Xie, C.; Wang, D.H. Ablation of transient receptor potential vanilloid 1 abolishes endothelin-induced increases in afferent renal nerve activity: Mechanisms and functional significance. Hypertension 2009, 54, 1298-1305. [CrossRef] [PubMed]

13. Ditting, T.; Freisinger, W.; Siegel, K.; Fiedler, C.; Small, L.; Neuhuber, W.; Heinlein, S.; Reeh, P.W.; Schmieder, R.E.; Veelken, R. Tonic postganglionic sympathetic inhibition induced by afferent renal nerves? Hypertension 2012, 59, 467-476. [CrossRef] [PubMed]

14. Haddock, R.E.; Hill, C.E. Sympathetic overdrive in obesity involves purinergic hyperactivity in the resistance vasculature. J. Physiol. 2011, 589, 3289-3307. [CrossRef]

15. Alvarez, G.E.; Beske, S.D.; Ballard, T.P.; Davy, K.P. Sympathetic neural activation in visceral obesity. Circulation 2002, 106, 2533-2536. [CrossRef] [PubMed] 
16. Tentolouris, N.; Liatis, S.; Katsilambros, N. Sympathetic system activity in obesity and metabolic syndrome. Ann. N. Y. Acad. Sci. 2006, 1083, 129-152. [CrossRef]

17. Skrapari, I.; Tentolouris, N.; Perrea, D.; Bakoyiannis, C.; Papazafiropoulou, A.; Katsilambros, N. Baroreflex sensitivity in obesity: Relationship with cardiac autonomic nervous system activity. Obesity 2007, 15, 1685-1693. [CrossRef]

18. Lee, E.; Jung, D.Y.; Kim, J.H.; Patel, P.R.; Hu, X.; Lee, Y.; Azuma, Y.; Wang, H.F.; Tsitsilianos, N.; Shafiq, U.; et al. Transient receptor potential vanilloid type-1 channel regulates diet-induced obesity, insulin resistance, and leptin resistance. FASEB J. 2015, 29, 3182-3192. [CrossRef]

19. Li, T.; Wang, G.; Hui, V.C.C.; Saad, D.; de Sousa Valente, J.; La Montanara, P.; Nagy, I. TRPV1 feed-forward sensitisation depends on COX2 upregulation in primary sensory neurons. Sci. Rep. 2021, 11, 3514. [CrossRef]

20. Kopp, U.C.; Cicha, M.Z.; Nakamura, K.; Nusing, R.M.; Smith, L.A.; Hokfelt, T. Activation of EP4 receptors contributes to prostaglandin E2-mediated stimulation of renal sensory nerves. Am. J. Physiol Renal Physiol. 2004, 287, F1269-F1282. [CrossRef]

21. Zhu, Y.; Xie, C.; Wang, D.H. TRPV1-mediated diuresis and natriuresis induced by hypertonic saline perfusion of the renal pelvis. Am. J. Nephrol. 2007, 27, 530-537. [CrossRef] [PubMed]

22. Sun, H.; Li, D.P.; Chen, S.R.; Hittelman, W.N.; Pan, H.L. Sensing of blood pressure increase by transient receptor potential vanilloid 1 receptors on baroreceptors. J. Pharmacol. Exp. Ther.. 2009, 331, 851-859. [CrossRef] [PubMed]

23. Shi, H.; Patschan, D.; Epstein, T.; Goligorsky, M.S.; Winaver, J. Delayed recovery of renal regional blood flow in diabetic mice subjected to acute ischemic kidney injury. Am. J. Physiol. 2007, 293, F1512-F1517. [CrossRef] [PubMed]

24. Roman, R.J.; Mattson, D.L.; Cowley, A.W., Jr. Measurement of regional blood flow in the kidney using laser-Doppler flowmetry. Methods Mol. Med. 2001, 51, 407-426.

25. Dunn, S.R.; Qi, Z.; Bottinger, E.P.; Breyer, M.D.; Sharma, K. Utility of endogenous creatinine clearance as a measure of renal function in mice. Kidney Int. 2004, 65, 1959-1967. [CrossRef]

26. Fardin, N.M.; Oyama, L.M.; Campos, R.R. Changes in baroreflex control of renal sympathetic nerve activity in high-fat-fed rats as a predictor of hypertension. Obesity 2012, 20, 1591-1597. [CrossRef]

27. Kopp, U.C.; Cicha, M.Z.; Yorek, M.A. Impaired responsiveness of renal sensory nerves in streptozotocin-treated rats and obese Zucker diabetic fatty rats: Role of angiotensin. Am. J. Physiol Regul Integr Comp. Physiol. 2008, 294, R858-R866. [CrossRef]

28. Marfella, R.; Nappo, F.; Marfella, M.A.; Giugliano, D. Acute hyperglycemia and autonomic function. Diabetes Care. 2001, 24, 2016-2017. [CrossRef]

29. de Lima, D.C.; Silveira, S.A.; Haibara, A.S.; Coimbra, C.C. The enhanced hyperglycemic response to hemorrhage hypotension in obese rats is related to an impaired baroreflex. Metab. Brain Dis. 2008, 23, 361-373. [CrossRef]

30. Arnold, A.C.; Shaltout, H.A.; Gallagher, P.E.; Diz, D.I. Leptin impairs cardiovagal baroreflex function at the level of the solitary tract nucleus. Hypertension 2009, 54, 1001-1008. [CrossRef]

31. McKernan, A.M.; Calaresu, F.R. Insulin microinjection into the nucleus tractus solitarii of the rat attenuates the baroreceptor reflex. J. Auton. Nerv. Syst. 1996, 61, 128-138. [CrossRef]

32. Rahmouni, K.; Haynes, W.G. Leptin and the cardiovascular system. Recent Prog. Horm. Res. 2004, 59, 225-244. [CrossRef] [PubMed]

33. Sanya, E.O.; Brown, C.M.; Dutsch, M.; Zikeli, U.; Neundorfer, B.; Hilz, M.J. Impaired cardiovagal and vasomotor responses to baroreceptor stimulation in type II diabetes mellitus. Eur. J. Clin. Investig. 2003, 33, 582-588. [CrossRef] [PubMed]

34. Ruiz, J.; Monbaron, D.; Parati, G.; Perret, S.; Haesler, E.; Danzeisen, C.; Hayoz, D. Diabetic neuropathy is a more important determinant of baroreflex sensitivity than carotid elasticity in type 2 diabetes. Hypertension 2005, 46, 162-167. [CrossRef]

35. Hajduczok, G.; Chapleau, M.W.; Johnson, S.L.; Abboud, F.M. Increase in sympathetic activity with age. I. Role of impairment of arterial baroreflexes. Am. J. Physiol. 1991, 260, H1113-H1120. [CrossRef]

36. Ying, Z.; Giachini, F.R.; Tostes, R.C.; Webb, R.C. Salicylates dilate blood vessels through inhibiting PYK2-mediated RhoA/Rhokinase activation. Cardiovasc Res. 2009, 83, 155-162. [CrossRef]

37. Imig, J.D. Eicosanoids and renal vascular function in diseases. Clin. Sci. 2006, 111, 21-34. [CrossRef]

38. Premkumar, L.S.; Raisinghani, M. Nociceptors in cardiovascular functions: Complex interplay as a result of cyclooxygenase inhibition. Mol. Pain 2006, 2, 26. [CrossRef]

39. Yang, D.; Luo, Z.; Ma, S.; Wong, W.T.; Ma, L.; Zhong, J.; He, H.; Zhao, Z.; Cao, T.; Yan, Z.; et al. Activation of TRPV1 by dietary capsaicin improves endothelium-dependent vasorelaxation and prevents hypertension. Cell Metab. 2010, 12, 130-141. [CrossRef]

40. Kumagai, K.; Suzuki, H.; Ichikawa, M.; Jimbo, M.; Murakami, M.; Ryuzaki, M.; Saruta, T. Nitric oxide increases renal blood flow by interacting with the sympathetic nervous system. Hypertension 1994, 24, 220-226. [CrossRef] 